\title{
EDITORIAL
}

\section{International Perspectives on Public Health}

\author{
Stuart C. Carr \\ Massey University
}

\author{
Ines Meyer \\ University of Cape Town
}

Aptly enough perhaps given a current global pandemic, this 2020 issue of International Perspectives in Psychology (IPP) is replete with responsive, relevant research on public health and well-being. The contents of the issue are further directly relevant to the United Nations Sustainable Development Goals (SDGs). In particular, they relate to ensuring healthy lives and promoting well-being for all at all ages (SDG-3 - Good Health and Well-Being) and to attaining access to decent work for all (SDG-8-Decent Work and Economic Growth; United Nations, 2020).

Building on a founding theme for $I P P$, we begin with a study of best practices in Global Mental Health (Hook \& Vera, 2020). This theme is instantiated by a study on the role of enculturation in help-seeking attitudes toward helping human services in Guam (De Luna \& Kawabata, 2020). Relatedly, the issue features a review of body image and appearance management behaviors among women in South Korea (Lin \& Raval, 2020).

Shifting more overtly to public health crises are two Policy Briefs. One of these concerns the use of Internet search engines to help predict, and possibly manage, pandemics and other health crisis (Ma-Kellams, 2020). A second, clearly related brief focuses, again preventatively, on how the workplace-in this case in rural and agricultural India-intersects with public health, and health promotion (Saxena \& Burke, 2020).

Underscoring this interconnectedness of work and well-being, our final contribution in this issue of IPP examines public attitudes toward relatively informal, often precarious and "radical" occupations (Groot \& Hodgetts, 2015; see also, Le, 2017). In this case, the scrutiny is on public attitudes toward people who are trying to earn a living through sex work in Thailand (Stenersen, Ovrebo, Adams, \& Hayes, 2020).

These contributions are timely indeed. They are innovative and responsive, interrelated, and integral to one another. Public health depends on decent work and vice versa. A single caregiver, precariously employed, may have to give up even that precarious job if their child's school closes, because they cannot afford childcare. This is just one example to illustrate that public health and decent work are interconnected. IPP is focused on finding ways to join such dots. That is precisely the ethos of our next two special issues. These will highlight interna-

Stuart C. Carr, School of Psychology, Massey University; Ines Meyer, School of Management Studies, University of Cape Town.

Correspondence concerning this article should be addressed to Stuart C. Carr, School of Psychology, Massey University, Aotearoa-New Zealand, Private Bag 102 904, North Shore MSC, Albany Village, Auckland, North Island 745, New Zealand. E-mail: S.C.Carr@massey.ac.nz 
tional perspectives on Sustainable Livelihood and Global Mobility (https://www .apa.org/pubs/journals/ipp/call-for-papers-human-mobility).

\section{References}

De Luna, J., \& Kawabata, Y. (2020). The role of enculturation on the help-seeking attitudes of Filipino Americans. International Perspectives in Psychology: Research, Practice, Consultation, 9, 84-95. http://dx.doi.org/10.1037/ipp0000127

Groot, S., \& Hodgetts, D. (2015). The infamy of begging: A case-based approach to street homelessness and radical commerce. Qualitative Research in Psychology, 12, 349-366. http://dx.doi.org/10.1080/14780887.2014.960984

Hook, K., \& Vera, E. (2020). Best practices in global mental health: An exploratory study of recommendations for psychologists. International Perspectives in Psychology: Research, Practice, Consultation, 9, 67-83. http://dx.doi.org/10.1037/ipp0000125

Le, T. N. (2017). Cultural considerations in a phenomenological study of mindfulness with Vietnamese youth and cyclo-drivers. International Perspectives in Psychology: Research, Practice, Consultation, 6, 246-260. http://dx.doi.org/10.1037/ipp0000077

Lin, K. L., \& Raval, V. V. (2020). Understanding body image and appearance management among adult women in South Korea within a socio-cultural context: A review. International Perspectives in Psychology: Research, Practice, Consultation, 9, 96-122. http://dx.doi.org/10.1037/ipp0000124

Ma-Kellams, C. (2020). Using Google Search volume to inform early detection interventions for public health crises: A policy brief. International Perspectives in Psychology: Research, Practice, Consultation, 9, 123-126. http://dx.doi.org/10.1037/ipp0000128

Saxena, M., \& Burke, M. M. (2020). Communicable diseases as occupational hazards for agricultural workers: Using experience sampling methods for promoting public health. International Perspectives in Psychology: Research, Practice, Consultation, 9, 127130. http://dx.doi.org/10.1037/ipp0000129

Stenersen, M., Ovrebo, E., Adams, K. L., \& Hayes, L. R. (2020). Foreigners' attitudes towards individuals who sell sex in Thailand: A prototype study. International Perspectives in Psychology: Research, Practice, Consultation, 9, 131-144. http://dx.doi .org/10.1037/ipp0000126

United Nations. (2020). Sustainable development goals knowledge platform. New York, NY: United Nations. Retrieved from https://sustainabledevelopment.un.org 